\title{
A juventude nas Jornadas de Junho em Alagoas: um estudo a partir de material jornalístico
}

\author{
Youth in June's Journey in Alagoas: \\ a study from journalistic material
}

\section{La juventud en las Jornadas de Junio en Alagoas: un estudio del material periodístico}

\author{
Sara Angemary Matias Maciel ${ }^{1}$ \\ sara_matias07@hotmail.com \\ Marcos Ribeiro Mesquita ${ }^{2}$ \\ marcos.mesquita@ip.ufal.br
}

\begin{abstract}
Resumo
Este trabalho teve como objetivo compreender as múltiplas leituras acerca da juventude que protagonizou as manifestações conhecidas como Jornadas de Junho, ocorridas em várias cidades brasileiras em 2013, focalizando suas dinâmicas no estado de Alagoas, a partir da análise de material midiático local. Assim, foram selecionadas e analisadas qualitativamente 42 notícias e artigos que noticiaram as manifestações em Alagoas de modo a compreender as concepções de juventude e sua ligação com a política, o entendimento acerca das mobilizações e as estratégias de luta política das manifestações que circularam na mídia objetivando conhecer como esses eventos foram noticiados e suas repercussões. Os resultados permitiram apreender três eixos de análise (Juventude e política, Dinâmica das mobilizações e Reivindicações) que foram importantes para compreendermos que a representação do jovem em sua interface com a política foi insuficientemente discutida e apontarmos para a necessidade de nos atentarmos para as novidades políticas trazidas pelas ruas.
\end{abstract}

Palavras chave

Juventude, participação política, jornadas de junho, protesto, análise documental.

Forma sugerida de citar: Maciel, S. A. M. \& Mesquita, M. R. (2016). La juventud en las Jornadas de Junio en Alagoas: un estudio del material periodístico. Universitas, XIV(1), pp. 173-195.

1 Psicóloga pela Universidade Federal de Alagoas (UFAL).

2 Professor do Programa de Pós-graduação em Psicologia da Universidade Federal de Alagoas (UFAL). 


\begin{abstract}
This work had as objective to understand the multiple readings about youth who starred the manifestations known as June's Journey, occurred in a lot of brazilian cities in 2013, focusing its dynamics in the state of Alagoas, from analysis of local media materials. Therefore, 42 news and articles which reported the manifestations in Alagoas were selected and analyzed to understand the conceptions of youth and its connection with the politics, the understanding about the mobilizations and the strategy of politic fight of manifestations which passed by the media, all this to know how these events were reported and its repercussions. The results allowed to capture three axis of analysis (Youth and politic, Dynamics of mobilizations and Claims) which were important to understand that the representation of young in its interface with politics was poorly discussed and we point to the need of attend to the political news brought the streets.
\end{abstract}

\title{
Keywords
}

Youth, political participation, June's Journey, protest, document analysis.

\section{Resumen}

Este estudio tuvo como objetivo comprender las múltiples lecturas sobre los jóvenes que organizaron las manifestaciones conocidas como las Jornadas de Junio, que tuvo lugar en varias ciudades del Brasil en 2013, centrándose en su dinámica en el estado de Alagoas, a partir del análisis de los materiales de los medios de comunicación locales. Por lo tanto, fueron seleccionados y analizados cualitativamente 42 artículos y noticias que informó las manifestaciones en Alagoas con el fin de comprender las concepciones de los jóvenes y su relación con la política, la comprensión de las movilizaciones y las estrategias de lucha política de las manifestaciones que han circulado en los medios de comunicación con el objetivo de saber cómo se informó de estos eventos y sus repercusiones. Los resultados aprenden tres ejes de análisis (Juventud y política, Dinámicas de las movilizaciones y Reclamos) que eran importantes para entender que la representación de los jóvenes en su interfaz con la política se discutió insuficientemente y señalaron la necesidad de nosotros para cuidar de las novedades políticas traído de las calles.

\section{Palabras clave}

Juventud, participación política, Jornadas de Junio, protesto, análisis documental.

\section{Introdução}

É comum na literatura, atribuir o desinteresse à dimensão institucional da política a questões ligadas à alienação e desinformação e essa abordagem é mais marcante quando se trata do engajamento político das gerações jovens contemporâneas, em relação às gerações passadas (Florentino, 2008). 
Ao se analisar a relação entre juventude e política, as discussões frequentemente situam-se em posições distintas, onde o jovem ora é apresentado como apolítico, apático e individualista, ora é apontado como um sujeito de experiências inovadoras, que resignifica a condição política e os modos de envolvimento com as questões públicas. Com a controvérsia desses debates realizados tanto no nível acadêmico, quanto no âmbito dos grupos sociais em geral, temos que, definitivamente, essa relação não é natural, nem para uma perspectiva, nem para outra (Mayorga, 2013).

Vemos, então, que ao se tratar dicotomicamente essa questão, as possibilidades de identificar os pontos que transversalizam a relação da juventude com a política dificilmente serão efetivados. Sob essa perspectiva, é pouco provável que alguns elementos importantes desta relação sejam percebidos, empobrecendo e limitando os olhares sobre a realidade - sempre plural em termos de experiência. Por outro lado, se a tratamos sem o binarismo das visões acima destacadas, podemos ampliar as possibilidades de interpretação das diferentes relações entre jovens e política no contemporâneo.

Assim, partimos da compreensão dos jovens como sujeitos historicamente situados que podem ou não participar de experiências no campo da participação, visto que esta relação entre jovens e política não está dada a priori, ela é necessariamente constituída na medida em que existem redes de sociabilidades que garantam o exercício de práticas educativas de participação, mobilização, debate e envolvimento com temas sociais. Compreendemos também que do mesmo modo em que existe uma diversidade de formas de ser jovem, também são plurais os modos destes se relacionarem com a política. Neste trabalho, priorizaremos a análise de uma experiência de participação política juvenil.

Para diferentes autores, a juventude vem sendo crescentemente compreendida como um espaço de interrogação das formas políticas construídas pelas gerações passadas, fato que nem sempre é avaliado positivamente, pois, em grande parte, acontece nas bordas das estruturas institucionais do sistema democrático (Augusto, 2008). Os questionamentos que a juventude faz acerca da política, muito vinculada a uma dimensão da democracia formal e representativa não parecem ser inválidos. Abramo \& Venturi (2000, p. 05) afirmam que não são os jovens que desconhecem a importância da política, mas antes, a forma predominante de se fazer política no país é que não os reconhece como possíveis interlocutores, produzindo em muitos deles um distanciamento. 
Podemos afirmar que há na literatura a percepção de que a participação política de significativa parcela da juventude vem percorrendo espaços diferentes dos institucionalizados e cumprindo novas agendas políticas que, nem sempre, são focalizadas pelas prioridades institucionais (Mesquita, 2009; Krischke, 2004; Abramo e Venturi, 2000). Tal fato não significa, entretanto, um desalinhamento político destes jovens, mas antes, uma resposta à falta de confiança no sistema político (Augusto, 2008).

Sempre com uma parcela significativa de participação nas mobilizações de rua, a juventude brasileira tem se mostrado favorável à ocupação de espaços públicos como forma de expressar seus descontentamentos, empenhando-se nas tradicionais passeatas e manifestações. Esses eventos demarcam formas atuais de participação que revelam características singulares e, muitas vezes, inéditas. Nesse sentido, as Jornadas de Junho deixaram alguns exemplos, como a pluralidade de conteúdos de reivindicação, a formação de assembleias populares em algumas cidades para pensar e decidir sobre o rumos do movimento, a inexistência de liderança única na constituição das Jornadas e a forte relação entre política e cultura percebida em diversas intervenções de coletivos organizados. Se esses elementos não são inéditos, saíram fortalecidos enquanto modo de atuar politicamente.

\section{A política das ruas}

A convocação às ruas e a ocupação dos espaços públicos demonstram uma real -e necessária- ampliação dos espaços de participação social, revelada pelas mobilizações populares. As mobilizações na esfera pública são manifestações tradicionais que, ora são visibilizadas (e midiatizadas), ora são ignoradas, mas sempre afirmadas como uma tradição de ocupação do espaço e de reivindicação popular. E muitos são os exemplos de profícuas e já tradicionais manifestações que agregam diferentes setores da sociedade, apontando o reconhecimento da mesma para com essa forma de expressão.

Essas mobilizações incluem ainda a participação de simpatizantes e anseiam produzir efeitos para os próprios manifestantes e para toda a sociedade civil, como um modo de pressão política dos mais significativos na realidade pública atual. A Marcha Nacional pela Reforma Agrária, a Parada da Diversidade, a Marcha da Reforma Urbana, a Marcha Mundial das Mulheres, a Marcha vinculada à III Cúpula dos Povos e a Marcha Zumbi +10 são alguns exemplos de movimentos fortemente articulados que produzem ou 
produziram importantes contribuições para a história das mobilizações de rua em todo o mundo (Scherer-Warren, 2006). Recentemente, fenômenos que foram notórios e que vimos se manifestar em vários pontos do planeta, despontando de forma enfática e, por vezes, sensacionalista nos noticiários, foram as recentes mobilizações impulsionadas, em sua maioria, por jovens que convocaram as mais diversas gerações a irem às ruas pelas mais variadas bandeiras (Rolnik, 2013).

No Brasil, as mobilizações iniciadas no mês de junho de 2013 (conhecidas como Jornadas de Junho) despontaram como uma surpresa no cenário político, tanto pelo número de pessoas que conseguiu reunir nas ruas, quanto pela sua aparição na imprensa depois da resposta truculenta da polícia nos primeiros dias de mobilização do Movimento do Passe Livre (MPL) em São Paulo, que tiveram como principal reivindicação a diminuição da tarifa do transporte público. Os protestos ocorreram em várias cidades do Brasil, com foco nas capitais dos estados e grandes cidades, mas também atingiram cidades de médio porte (Moreira e Santiago, 2013). Em Alagoas, as mobilizações chegaram também em cidades de pequeno porte e em rodovias de acesso a diversos municípios.

Caminhando em paralelo às diversas mobilizações cotidianas em todo o país, o despertar das manifestações de junho não surgiu do nada. Como indica Rolnik (2013), a resistência urbana, o próprio MPL, os movimentos semteto e os movimentos estudantis são exemplos de uma geração de movimentos urbanos que, entre "catracaços", ocupações e manifestações articulam-se em redes mais amplas. As mobilizações de junho de 2013 são resultados também de uma série de manifestações iniciadas em 2003 na cidade de Salvador, conhecida como a Revolta do Buzu, que reclamava na prática, ali nas ruas, um distanciamento dos moldes hierarquizados e explicitavam, ainda que de forma embrionária, outro tipo de organização (MPL-SP, 2013).

Em junho de 2013, o primeiro protesto promovido pelo MPL foi recebido pela imprensa e governantes de maneira muito negativa, desembocando numa repressão policial cruel. A grande mídia, inicialmente, intitulou os manifestantes de vândalos e, depois, fez um jogo de apoio em algumas situações, quando convinha, dado o apoio de parcela significativa da sociedade que aderiu ao movimento indo às ruas ou se posicionando favorável a ele nas redes sociais e outros espaços. Mas, de um modo geral, criminalizou o movimento e reforçou uma narrativa conservadora junto aos acontecimentos. Com relação aos governos, além de demonstrarem certa fragilidade da 
democracia brasileira, eles revelaram a inabilidade de oportunizar o diálogo com a sociedade diretamente, desqualificando o movimento de protesto (Moreira e Santiago, 2013).

As manifestações arrastaram às ruas centenas de pessoas e grupos políticos, porém, tiveram como principal característica a participação de homens e mulheres não integrados aos movimentos sociais tradicionais. A participação da juventude, em especial de estudantes universitários e secundaristas foi expressiva. As várias reivindicações trazidas nos cartazes também foi um elemento importante das mobilizações, revelando a multiplicidade de posições sobre a realidade brasileira, bem como a falta de um único direcionamento e de lideranças dos movimentos sociais populares na cena política.

Moreira e Santiago (2013, p. 14) afirmam que essas mobilizações "desencadeiam novas formas de ação e participação pois, tais momentos vislumbram uma descontinuidade nos formatos de participação política, além de questionar os processos de representação da democracia representativa". Faz-se necessário, então, que estejamos atentos para com as novidades políticas conduzidas pelas ruas, tanto da perspectiva político institucional, ao questionar-se a ausência de representatividade dos governos, quanto da perspectiva da dinâmica da sociedade civil, ao problematizarem-se os formatos de representação e manifestação, com um intenso sinal da democracia representativa. A hostilidade, as divergências e ofensas feitas para os movimentos sociais tradicionais e organizações partidárias que estiveram nas mobilizações muito falam dessas problematizações e descontentamentos (Moreira e Santiago, 2013).

Assim sendo, o presente trabalho objetivou compreender os múltiplos olhares e leituras acerca da juventude que protagonizou as Jornadas de Junho, focalizando suas dinâmicas e movimentos no estado de Alagoas e perpassando uma leitura crítica da participação política juvenil na contemporaneidade. Deste modo, foram analisadas as concepções de juventude que circularam nas notas midiáticas, a pluralidade de reivindicações trazidas por esses jovens e a forma de organização dos atos - através de material elaborado por um órgão jornalístico alagoano.

\section{Método}

Este trabalho deu-se, metodologicamente, em dois momentos. Inicialmente, foi realizado um levantamento de materiais midiáticos digitais que no- 
ticiaram essas mobilizações em um veículo jornalístico alagoano, objetivando conhecer como esses eventos foram noticiados e suas possíveis repercussões. Entendemos que apesar dos jornais divulgarem um caráter de imparcialidade, eles não estão isentos dos valores e olhares do grupo que participam. Ainda assim, julgamos como necessária a problematização dessas expressões singulares por considerar que tais materiais são documentos públicos que detém o registro de determinada cultura e sociedade (Flick, 2009). Além disso, o olhar crítico sobre o material de análise permeou nosso trabalho.

O meio de comunicação selecionado foi um jornal de grande circulação no estado, a Gazeta de Alagoas, que disponibiliza sua versão impressa também online. A busca foi realizada sem uso de descritores; ao invés disso, foram analisadas todas as edições publicadas entre os dias 01/06/2013 e 31/07/2013. Deste modo, foram pesquisadas e incluídas para a análise matérias e artigos que tivessem relação com a temática das manifestações, considerando que estas iniciaram-se no estado no dia 13/06/2013 e tomando o dia 11/07/2013 como a data da última manifestação. Foram encontrados 71 materiais midiáticos digitais que noticiaram as manifestações em Alagoas (na capital, em mais 03 municípios e em rodovias de acesso a outras 12 cidades). Destes, foram selecionadas 42 matérias, por se aproximarem mais dos objetivos deste trabalho. Destes, 36 eram artigos com notícias sobre as manifestações considerando sua dimensão nacional, mas, e principalmente, os aspectos do movimento em Alagoas; 04 editoriais e 02 textos de colunistas do jornal.

Num segundo momento, as informações obtidas a partir do material selecionado foram analisadas qualitativamente, segundo a produção existente acerca da temática de juventude e participação política, através de análise do conteúdo. A análise se deu em duas etapas: primeiramente foram ordenadas as informações obtidas a partir do material midiático, com a elaboração das categorias emergentes de análise e, depois, foi realizada uma articulação entre os temas propostos nos objetivos, as observações e a literatura disponível na área.

As três categorias de análise foram concebidas a partir da leitura dos materiais selecionados, observando-se quais temáticas eram mais recorrentes e atentando-se aos objetivos propostos. A primeira delas, "Juventude e política", foi pensada para que se compreendesse a relação que os jovens possuem com a política, de acordo com as interpretações feitas pela redação do jornal e os autores dos artigos. As segunda e terceira categorias, "Dinâmicas das mobilizações" e "Reivindicações", foram estabelecidas para que 
se identificassem as formas de organização e movimentações dos atos e a pluralidade de pautas trazidas pelos jovens no contexto alagoano.

\section{Análises e resultados}

Os dados aqui apresentados foram discutidos a partir das categorias de análise que elencamos e que serão esmiuçadas a seguir. Em cada exemplo de fala apresentado seguem-se as iniciais do sujeito, o título da matéria ou artigo e a data de publicação. Os extratos dos editoriais são indicados por "Ed".

\section{Juventude e política}

Um importante elemento das manifestações dos últimos anos que ocorreram mundo afora foi a participação da juventude, e, mais ainda, o protagonismo que esse segmento apresentou nas mobilizações. Outros segmentos também ocuparam as ruas nos protestos, mas os atos foram majoritariamente organizados por jovens e, no Brasil, isso não foi diferente (Moreira e Santiago, 2013). No que diz respeito à relação entre juventude e política, essa conexão tem seguido uma multiplicidade de interpretações, que variam entre uma perspectiva "romântica" e uma perspectiva depreciativa, a depender da forma como os jovens lidam com variados contextos socio-históricos (Augusto, 2008).

Apesar de não enxergarem os jovens como essencialmente apolíticos ou alheios aos processos democráticos, as poucas discussões que apontam para as representações do jovem em sua interface com a política, nos materiais analisados, acompanharam as concepções de juventude que falam dessa categoria como sujeitos utópicos, sem direcionamentos específicos e politicamente limitados. Em espaços do editorial e no discurso de um dos escritores do jornal, pode-se visualizar essas concepções: "No mais, a turma não sabe ainda por aonde vai, mas sabe que não quer ir pelos velhos caminhos que lhes seriam apontados por velhas e "novas' lideranças" (Ed, O que mesmo quer dizer essa voz rouca das ruas?, 18 jun 2013); "Então, jovens idealistas se uniram, de todas as classes sociais e de todas as idades, a fim de dar um basta nessa difícil e incompreensível situação" (M.H., Sonhos da juventude por um Brasil melhor, 30 jun 2013).

Em outro momento do editorial essa perspectiva é reforçada: 
[...] fica evidente que a garotada não imagina um amanhã que não seja a continuidade da pândega cidadã do hoje. Algo como um carpe diem permanente, onde a velha bandeira dos centavos a menos já não serve e, para tal circunstância, vem a calhar a profusão de nobres causas explicitadas em incontáveis cartazes artesanais. Educação, saúde, ética, sustentabilidade, desenvolvimento, emprego, passe livre, maiores salários, menores obrigações, lazer, cultura, energia barata, wireless livre em todas as cidades, ingressos grátis para todos nos jogos da Copa, fim das mordomias em todos os níveis, fim da corrupção, descriminalização das drogas... Que mais? (Ed, O sucesso nas ruas e os rumos a tomar, 21 jun 2013).

Além da visão acima destacada, e em contrapartida, outras colocações apontam para um reconhecimento da luta política que a juventude -mas não só ela-visibilizou: "As manifestações não partiram do zero, elas trazem história. Existem movimentos sociais que reivindicam várias coisas há muitos anos" (E.A., O povo espera por respostas rápidas, 23 jun 2013). Ou ainda:

Muitas bandeiras e muitos sem bandeiras ocupam juntos a praça pública, ou seja, colocam as suas demandas para o conjunto da população e ocupam os lugares de quem tem algo a dizer, buscando criar novos vínculos sociais (E.A., O povo espera por respostas rápidas, 23 jun 2013).

Um discurso nos permite, ainda, afirmar que essa relação entre juventude e política é também vista como promessa de uma nova forma de participação popular:

O que todos estamos vendo são novas marcas ou caminhos para a expressão da vontade de muitos grupos sociais, que nem sempre frequentam os canais regulares de participação política. Elas também são uma forma de dizer que muitas instituições políticas não estão funcionando bem (E.A., O povo espera por respostas rápidas, 23 jun 2013).

Embora sejam poucos (04 artigos, sendo 02 de noticiário comum, 01 do editorial e 01 de um colunista do órgão) os discursos que aparecem no jornal pesquisado e que falam da relação entre a juventude e a política, essas falas demarcam perspectivas bem distintas dos entrevistados e do editorial. Por um lado, a crítica recai sobre a "natureza" utópica e indecisa dos jovens, que reafirma a ideia de que eles não são capazes de construir seus próprios meios de participação e de opinar sobre os rumos da sociedade. Por outro, o discurso remete às lutas anteriores que a juventude ajudou a visibilizar e aposta 
nessa participação popular construída também por essa categoria como uma forma de revelar o desencantamento com as instituições políticas.

No entanto, com os reduzidos dados nessa categoria de análise, consideramos que a representação da relação entre juventude e política foi insuficientemente discutida, num material elaborado por um órgão que é formador de opinião. Não compreendemos se, nesse caso, os sujeitos convidados a falar não problematizaram a questão -e isso já nos diz algo, pois a voz do próprio jovem não faz eco nas linhas do jornal (a não ser para explicitar as estratégias de organização do movimento) - ou se a imprensa não fez disso uma questão. Contudo, apesar do jornal pesquisado não ter se implicado muito nessa discussão, muitos são os elementos passíveis de problematização a partir das experiências da juventude nessas manifestações.

Grupos sociais como os que organizaram as Jornadas de Junho estão cada vez mais visíveis nas ocupações de rua mundo afora. Assim como nessas manifestações no Brasil, grupos participantes de movimentos como o $15 \mathrm{M}$ na Espanha e o Occupy Wall Street em Nova York pregam a inviabilidade de modelos de participação verticais, centralizados e propõem novas formas que favoreçam práticas horizontais de tomadas de decisão, sem personificação de lideranças, nem comando de partidos e comitês centrais (Silva, 2014).

Nessa "nova cultura participativa", que aborda Beaskoetxea (2008 apud Silva, 2014), uma característica essencial é o "furor anti-institucional" (idem) que se sobressai nas ações dos jovens que buscam outro sentido para a participação política. Os jovens associam seu descontentamento a uma repulsa aos sistemas políticos, aos partidos clássicos e às formas tradicionais de organização política, inclusive de certos movimentos sociais e sindicais que, muitas vezes, são hierarquizados e/ou ligados ao aparelho estatal.

Não é de se surpreender, então, que nas assembleias e ocupações que acompanharam essas manifestações, foi comum a escolha dos jovens pela autogestão como base organizativa das atividades que eles propuseram, o que funciona também como contraponto às críticas que fazem à maneira como os procedimentos decisórios da política acontecem, principalmente no que dizem respeito à representatividade (Silva, 2014).

Vemos, então, que as críticas a uma juventude esvaziada de sentido político não fazem sentido. Alguns estudos (Brenner e Carrano, 2008) versam sobre essa questão e apontam que, mesmo que as circunstâncias sociais e econômicas queiram manipular as formas de resistência desses jovens, estes 
vêm-se revelando flexíveis a essas condições, adaptando-se e engendrando outros processos de participação.

Segundo Dayrell e Carrano (2008, p. 18), essas novidades nas formas de participação dos jovens apontam para um contexto de crise e transformação no âmbito político em que "a ação coletiva dos jovens, bem como os movimentos sociais, podem estar ocorrendo de formas múltiplas, variáveis e com níveis diversos de intervenção no social, muitas vezes de forma fluida e pouco estruturada".

Com isso, as mobilizações vistas nas ruas do Brasil, ao manifestarem uma variedade de reivindicações, demonstraram o descontentamento do povo com o modelo de representação política e a postura de seus representantes, mas também apontaram para novas formas de ação e de organização política. A apresentação de propostas claras e sistematizadas pode não ter vindo imediatamente, porém, é necessário que se atente ao que pode ser destacado no cenário dessa cultura participativa (Moreira e Santiago, 2013).

Uma pesquisa de opinião pública (Latinobarômetro, 2004 apud Abramovay et al, 2004) indicou que o distanciamento da juventude das frentes tradicionais da política acontece, principalmente, por questões de gestão relacionadas à inexistência de transparência das instituições e aos eventos de corrupção. A mesma pesquisa apontou ainda a preferência dos jovens por campos identitários e culturais como gênero, raça, ecologia, direitos sexuais e digitais e o movimento Hip-Hop. Esses eixos e os elementos de comunicação como redes virtuais, fóruns e ONGs, para muitos, vem caracterizando uma nova configuração da prática política juvenil.

A questão crucial, então, não passa pela falta de participação do jovem no campo da política, mas sim pelos formatos -oficializados ou não- dessa participação. Vemos sim, que a juventude quer ser protagonista da história do seu país e de suas próprias vidas e, como afirmaram os integrantes do MPL-SP (2013, p. 16): "É assim, na ação direta da população sobre sua vida -e não a portas fechadas, nos conselhos municipais engenhosamente instituídos pelas prefeituras ou em qualquer uma das outras artimanhas institucionais-, que se dá a verdadeira gestão popular”.

A prática concreta da gestão popular, segundo os militantes do MPL-SP (2013) foi vivenciada nas manifestações dos diversos cantos do país e a descentralização da organização dessas lutas apontou para uma outra forma de organização não só do transporte, mas da cidade e da sociedade como um todo. 
Para Harvey (2013), o tipo de cidade que desejamos e construímos nos fala também do tipo de sujeito que desejamos nos tornar. A construção de um espaço qualitativamente diferente do que vivemos reflete a liberdade de fazer e refazer as nossas cidades e a nós mesmos -se não estivermos contentes com o modo que vivemos-, sendo esta, um dos mais magníficos de todos os direitos humanos.

A relação intensa que o movimento das Jornadas estabeleceu com os espaços públicos foi, por demais, evidente. A ocupação das ruas, as assembleias em praças e embaixo de viadutos e a ocupação de algumas casas legislativas expressam esse vínculo. Em Alagoas, além das ruas e rodovias, o movimento também se utilizou de espaços públicos como o espaço cultural da Universidade Federal de Alagoas, por exemplo, para reunir e decidir sobre os passos das manifestações. A ocupação desses lugares viabiliza a implementação de esferas realmente públicas, transformando praças e ruas em espaços de discussão do povo, com o povo e para o povo, influenciando a opinião pública e transformando esses espaços em autênticas arenas para a participação política (Moreira e Santiago, 2013).

Como dissemos acima, poucas foram as vezes em que as matérias do jornal referido trouxeram um debate acerca dessas representações que relacionam os jovens à/s política/s. Se por um lado, expressa muitas vezes a superficialidade da informação rápida, instantânea, também pode demonstrar uma ausência mesmo de uma discussão que acontece cotidianamente nos meios sociais e acadêmicos acerca desta relação no contemporâneo. Vemos, então, que uma maior reflexão sobre o papel das mídias se faz necessária.

À luz do paradoxo redes sociais versus velha mídia e de uma cultura política que desqualifica seus próprios princípios e representantes, é essencial olhar atentamente o comportamento da velha mídia na cobertura das mobilizações. O poder de convocatória das novas mídias marcou presença forte na organização dos protestos, mas, mesmo não tendo um lugar marcante na velha mídia, os jovens que protagonizaram as manifestações precisaram sujeitar-se a ela para atingir uma maior visibilidade pública, ou seja, para serem inseridos no espaço que forma as opiniões públicas (Lima, 2013).

Segundo Lima (2013), no Brasil, a velha mídia praticamente não oferta espaços que suscitem o debate de questões de interesse público -diferente do que acontece em outras democracias- e nem mesmo oferecem um serviço de ouvidoria que abranja as expressões daqueles não representados, salvo raras exceções na mídia impressa. A partir do trabalho dessas velhas 
mídias, faz-se indispensável, então, que se reflita sobre o tipo de cobertura política que vem sendo realizada no país e sobre que objetivos ela possui. É essencial que se considerem as fronteiras entre uma cobertura sistematicamente contrária à política e seus atores e os perigos de ruptura do próprio sistema democrático que isso acarreta.

Tudo isso nos faz perceber a importância das novas tecnologias de comunicação na organização e propagação desses atos, funcionando não apenas como ferramentas de descrição e convocação, mas, mais ainda como meio capaz de construir e reconstruir a realidade. A atuação através dessas redes permite não apenas notificar ou reportar algo, mas também articular e modificar situações e isto, paulatinamente, modifica também a forma de se fazer política e os modos de participação social (Sakamoto, 2013).

\section{Dinâmicas das mobilizações}

Para além do intenso protagonismo da juventude, as Jornadas de Junho revelaram outros elementos que foram bastante significativos na construção e repercussão dessas mobilizações. Muitos se perguntaram como um movimento sem lideranças definidas -e que negava obstinadamente as categorias partidárias- conseguiu se impor de tal maneira no cenário político nacional, alcançando também o apoio de movimentos brasileiros no exterior. Para melhor compreendermos os movimentos dessas mobilizações, apresentamos aqui um breve relato linear das manifestações e elencamos características que foram essenciais nessas dinâmicas. Como tivemos um maior número de informações nos resultados dessas próximas categorias, optamos por relatálas de modo descritivo, ao passo em que serão feitas as articulações e análises a partir da literatura disponível.

\section{Linha do tempo / Atores}

Antes mesmo de ser anunciado o aumento da tarifa do transporte público em Alagoas, o povo já estava nas ruas. Pouco antes da metade do mês de junho de 2013, o centro da capital e algumas das principais avenidas e ruas da cidade presenciaram as manifestações convocadas pelo MPL. Os rumores sobre o aumento do preço da passagem que atinge não apenas estudantes, mas, também, trabalhadores que dependem do transporte público, levaram às ruas 
do estado centenas e milhares de pessoas que, com os rostos pintados e munidos de cartazes, bradavam suas reivindicações. Em Alagoas, entre junho e julho de 2013, ocorreram doze manifestações em diferentes cidades. Sete destas aconteceram na capital do estado (Maceió), duas no município de Arapiraca, uma em União dos Palmares e duas em Marechal Deodoro.

Apesar de, no início, as manifestações terem sido organizadas pelo MPL, as dimensões que essas tomaram em regularidade e intensidade fizeram com que muitos modificassem suas opiniões sobre os eventos e também juntassem-se aos jovens que conduziam os protestos (Nogueira, 2013). As lideranças estudantis em Alagoas aprovaram a participação de muitas categorias em inserir-se nas mobilizações, levando em consideração o fato das manifestações serem de toda a sociedade, como afirma uma militante da Assembleia Nacional dos Estudantes Livres (ANEL): "As passeatas estão seguindo caminhos que não são só dos estudantes. Os militares, como outros trabalhadores, são bem-vindos" (L.C., Maceió terá novo protesto amanhã. MANIFESTAÇÃO. Militares decidiram se juntar ao movimento social que toma conta de todo o país, 25 jun 2013) . $^{3}$.

O MPL deu início, então, ao movimento que continuou muito mais amplo e posteriormente alcançou entidades sociais e sindicais que somaram-se ao coro das vozes nas ruas. Em Alagoas, o que se iniciou com o próprio MPL, a ANEL e estudantes não filiados, terminou por desembocar numa série de mobilizações que contou com a participação de trabalhadores, entidades sindicais e sociais, funcionários públicos, lideranças da sociedade civil organizada, militantes partidários, policiais civis e militares, bombeiros, representantes de várias categorias de classe, rodoviários, movimentos sociais sem-terra e índios.

Os movimentos sociais sem-terra, os rodoviários e os índios uniram-se ao movimento impulsionado pelas ações de junho, no Dia Nacional de Lutas e Paralisações (11 de julho), com a convocação das centrais sindicais para uma greve geral. Segundo Secco (2013), essa greve não acontecia desde 1991 e cerca de 200 mil pessoas participaram das mobilizações em pelo menos 157 cidades. E, embora o número de manifestantes fosse menor que

3 Em Maceió, ainda que pontualmente, os militares através de suas associações de oficiais, subtenentes, sargentos, cabos e praças também participaram das manifestações reivindicando investimentos em segurança pública e da PEC 300, que propõe a criação do piso único para militares nos Estados. Como destacado na matéria do jornal em destaque "“A sociedade precisa compreender que nosso papel não é apenas repressivo. Vamos fortalecer o movimento dando visibilidade às nossas reivindicações', disse o presidente da Associação dos Cabos e Praças Militares de Alagoas, cabo Wagner Simas". 
o das Jornadas de Junho, a abrangência geográfica do dia 11 de julho foi maior, paralisando os transportes públicos em algumas capitais e bloqueando rodovias em grande parte dos estados da federação. Em Alagoas, diversas categorias manifestaram-se em Maceió, reunindo milhares de pessoas nas ruas e outras mobilizações aconteceram também em rodovias de acesso a outros doze municípios (Rio Largo, Maragogi, Japaratinga, Flexeiras, Joaquim Gomes, Murici, Messias, Atalaia, Arapiraca, Craíbas, Pão de Açúcar e Porto Real do Colégio).

\section{Repúdio aos partidos e ausência de lideranças}

Outros fatores que chamaram a atenção nas manifestações de junho foram a falta de lideranças bem definidas conduzindo os eventos e o repúdio aos partidos políticos. A ausência das tradicionais organizações partidárias ou mesmo dos movimentos sociais revelou-se como novidade e diferenciou as Jornadas de outras mobilizações já ocorridas no país. Esse fato demonstrou também uma interessante capacidade de agregar diversos segmentos societários que essas manifestações proporcionaram, rompendo com o corporativismo incorporado em atos anteriores (Moreira e Santiago, 2013).

Em Alagoas, com relação aos atos de repúdio aos partidos políticos, se reproduziu o que aconteceu nacionalmente: alguns manifestantes não só evitaram a presença de militantes partidários, como também impediram que esses sujeitos participassem das mobilizações e/ou lançaram rumos diferentes aos protestos caso os militantes estivessem presentes. Como afirma uma entrevistada do jornal analisado:

Muito se tem falado em 'movimento apartidário' e acho que este não é o melhor adjetivo. Está claro que não há um único grupo que detém de forma hegemônica o comando do movimento -isto é uma evidência. Outra coisa é difundir uma ideia de negação da importância de partidos dentro do movimento-o que é irreal, pois partidos existem de fato e sua principal função é fazer a ponte entre o sistema político e os grupos sociais, portanto, eles têm direito à participação nas manifestações (E.A., O povo espera por respostas rápidas, 23 jun 2013).

É sabido que a participação dos militantes partidários nas manifestações não poderia ser impedida, no entanto, a crítica agressiva aos partidos e os episódios de violência que se sucederam nas mobilizações podem apontar 
para um repúdio à forma atual de se fazer política no país, como podemos visualizar no discurso de um dos seus articulistas que escreveu ao jornal: "As manifestações repudiaram os partidos políticos que tentaram aproveitar-se das mesmas e demonstraram como os eleitos estão distantes dos eleitores" (M.M., Panis et circenses, já não basta, 22 jun 2013).

Com isso, a postura antipartidária amplificada nas manifestações não foi uma rejeição suicida à política, mas a um modelo característico do fazer dos políticos: medíocre, distante dos interesses da sociedade e restrito às negociatas pessoais e de grupos empresariais, o que acaba em corrupção e desmoralização dos mandatos políticos (Amaral, 2013).

A hostilidade dos manifestantes contra quem empunhava uma bandeira nas mobilizações não necessariamente refletiu as inclinações desses contra o sistema partidário, mas antes contra as organizações clássicas que simbolizam a autoridade como um todo (Sakamoto, 2013).

As críticas podem ter sido hostis, as divergências de opinião também oscilaram bastante entre os manifestantes e muitos não concordaram com os atos de violência explícita que aconteceram nos protestos ${ }^{4}$. No entanto, para Moreira e Santiago (2013) os insultos aos movimentos sociais tradicionais que se fizeram presentes nas manifestações, para além de sua agressividade, serviram muito mais para revelar um enorme questionamento e descontentamento quanto à ausência de representatividade do Congresso Nacional e quanto à forma de organização da sociedade civil, quando se questionam os modelos de representação e de mobilização, com um expressivo sinal da democracia representativa.

Silva Neto (2013) também comunga dessa ideia e afirma: "o apartidarismo presente nas manifestações pode indicar dois possíveis caminhos: a recusa ao atual sistema partidário, daí se falar em "Reforma Política”, e, de uma maneira geral, ao desencanto com a nossa democracia representativa $[\ldots]^{\prime \prime}$ (p. 24).

4 Em Maceió, na terceira grande manifestação ocorrida, militantes de partidos políticos e associações clássicas dos movimentos sociais foram hostilizados: palavras de ordem contrárias à sua participação na passeata e focos de agressão física para com alguns destes militantes dividiu a manifestação em duas. Uma parte, com a participação dos partidos e outros movimentos sociais finalizou seu percurso no centro da cidade; a outra, mudou a trajetória original e encerrou com um grupo menor de manifestantes na orla da cidade. 


\section{Redes sociais}

Acompanhando as mobilizações nacionais, as manifestações em Alagoas também foram organizadas pelas redes sociais, reafirmando o poder de convocatória, de multiplicação dos canais de informação e de denúncia das novas mídias, apontando para a possibilidade de construção de outras narrativas junto a um público que as acessa cotidianamente. Alguns estudiosos apontam as similaridades entre as Jornadas de Junho e as manifestações que aconteceram no Oriente Médio, em 2010, no que se refere ao grande uso das redes sociais em favor do movimento e chamaram os eventos brasileiros de "Primavera Brasileira", fazendo alusão à "Primavera Árabe" (Rodrigues, 2013).

Alguns órgãos da imprensa nacional e internacional (como sites de notícias e de ONGs) afirmam que as manifestações de junho foram o maior fenômeno de mobilização popular desde as Diretas-Já e apontam os atos recentes como referências de um país novo, politizado e democrático, diferindo das manifestações dos anos 90 pela forma como a sociedade usou dos dispositivos midiáticos em benefício próprio (Almeida, 2013).

Há quem afirme que esse foi o diferencial e a causa dos atos de junho, no entanto, como aponta o editorial do jornal analisado:

Uma tolice, posto esses meios serem apenas instrumentos através dos quais fluem as motivações verdadeiras. Mobilizações maiores (como as Diretas Já) empolgaram muito mais milhões de brasileiros numa época onde nem telefonia móvel existia (Ed, O que mesmo quer dizer essa voz rouca das ruas? 18 jun 2013).

Para Amaral (2013), a novidade, portanto, não é a existência dessas estruturas midiáticas, mas sim a mudança qualitativa do seu uso que permite mobilizar e, hoje, constitui-se no principal órgão de imprensa verdadeiramente livre de controle ideológico, pois perpassa diversas tendências do pensamento e veicula toda e qualquer opinião, distribuindo-se nos mais variados pontos do planeta. As redes sociais possibilitam a multiplicação dos canais de informação, tornando cada sujeito responsável por seus próprios conteúdos, que podem ser acessados por um público muito mais abrangente do que o público dos dispositivos clássicos da imprensa tradicional. Esse discurso também pode ser visualizado numa expressão do editorial que afirma que "O fato inquestionável é que, via os meios de comunicação individualizados e populari- 
zados, ficou mais fácil mobilizar. Mas as convocações só são atendidas quando em torno delas se estabelece interesses e objetivos unificadores" (Ed, O que mesmo quer dizer essa voz rouca das ruas?, 18 jun 2013).

Espaços virtuais como Facebook, Twitter, Instagram, blogs e outros sítios possibilitaram o nascimento das manifestações, sua organização e, também, discussões que aconteceram distantes do discurso jornalístico, que foi inúmeras vezes criticado por deturpar a realidade das mobilizações, reafirmando estereótipos e contribuindo para a desinformação. Cada sujeito, pôde, apenas com a posse de um celular, produzir uma diversidade de materiais e repassá-los em tempo real, permitindo a criação de registros paralelos aos feitos pelas mídias clássicas de comunicação. Esses registros apresentaram olhares distintos da grande mídia, que, geralmente, está vinculada a interesses e intencionalidades hegemônicas das empresas midiáticas (A1meida, 2013).

Castro e Abramovay (2009) trazem ainda que, em paralelo com as novidades tecnológicas de participação política, deve-se analisar também o que há de novo nos portais governamentais, que atraem os cidadãos reafirmando o sentido da participação política e atuam como militantes virtuais, oportunizando a comunicação e participação de todos.

\section{Reivindicações}

A ocupação das cidades no caso das Jornadas de Junho, segundo Rolnik (2013: 08), se deu por diferentes sentidos: "[...] no decorrer dos protestos, houve uma disputa nos cartazes empunhados pelo conjunto heterogêneo que ocupou as ruas, e uma guerra de interpretações e vozes fez emergir não uma, mas uma infinidade de agendas mal resolvidas, contradições e paradoxos".

Em Alagoas, a principal reivindicação das mobilizações, inicialmente, seguiu o mesmo mote das pautas nacionais: contra o aumento do preço da passagem do transporte coletivo. Em paralelo, outras bandeiras foram surgindo e também tiveram espaço nas manifestações, são elas: o passe livre estudantil; a tarifa zero para todos nos fins de semana; uma crítica aos gastos públicos com a Copa do Mundo, indicada na expressão "não vai ter Copa"; por melhorias no transporte coletivo e mobilidade urbana; contra a violência; contra à corrupção; por maiores investimentos em saúde, educação e segurança; em defesa do meio ambiente; contra a PEC 37; em 
defesa da PEC 300; por uma reforma urbana; pelo veto ao Projeto de Lei 268/2002 (Ato Médico).

Algumas dessas reivindicações, como o Fora Feliciano e o descontentamento com os gastos com o mundial de futebol, surgiram no país em várias manifestações antes mesmo de junho, porém, essas pautas não alcançaram grande visibilidade. Também como forma de chamar atenção das esferas institucionais para essas questões, diversas pautas surgiram, mas, muitas delas, nada suscitaram.

A revogação do aumento da passagem como primeira pauta conquistada também deu margem para que as mais diferentes bandeiras surgissem. O preço das passagens foi reduzido em mais de 100 cidades e, ainda assim, as mobilizações continuaram (Secco, 2013). Em Maceió, os organizadores das manifestações alegaram que "o discurso da presidente Dilma Rousseff, que firmou um pacto com os governadores e prefeitos do Brasil, serviu para fortalecer a extensa pauta de reivindicações" (M.R., Data de nova manifestação em Maceió é adiada. MUDANÇA. Entidades se reuniram ontem para discutir protesto, 26 jun 2013).

A partir do Dia Nacional de Lutas e Paralisações (11/07) outras pautas também surgiram nas manifestações no estado: pelo fim do ato previdenciário e aumento das aposentadorias; pelo fim dos leilões do petróleo; pela redução da jornada de trabalho sem redução de salários; pela reforma agrária e pela derrubada do projeto de lei $n^{\circ} 4330$ (terceirização no serviço público); contra a gestão do governador em exercício; pela destinação de $10 \%$ do orçamento da União para a saúde pública e de $10 \%$ do PIB para a educação pública; contra a deficiência na política de reforma agrária.

Segundo Žižek, deve-se evitar o essencialismo ao se pensar que existe um objetivo único "real" perseguido pelos manifestantes, alguma coisa que fosse capaz de, assim que concretizado, pudesse diminuir a sensação de mal-estar de todos. Para ele, "o que a maioria dos manifestantes compartilha é um sentimento fluido de desconforto e descontentamento que sustenta e une demandas particulares" (Žižek, 2013, p. 103). Isso também pode ser constatado no discurso de uma entrevistada do jornal analisado, que afirma que a pluralidade de reivindicações não atrapalha. Segundo ela, "não tem como as manifestações darem em nada. Elas estão escancarando várias questões que fazem parte da vida de milhões de brasileiros e que, num cer- 
to sentido, andavam sendo silenciadas" (E.A., O povo espera por respostas rápidas, 23 jun 2013 ).

Muitas foram as conquistas que as Jornadas de Junho possibilitaram. Em Maceió, muitos pontos da mobilidade urbana entraram em pauta nas agendas políticas após a ocorrência dos protestos e depois das medidas anunciadas pela Presidente da República, como melhorias no sistema de transporte público e a facilitação do fluxo de veículos na cidade. Além disso, o poder de pressão social repercutiu no não aumento da tarifa na cidade, naquele momento.

Em âmbito nacional, outras vitórias também foram alcançadas. No Legislativo Federal, a derrubada da PEC 37, que limitava as investigações do Ministério Público (MP), foi um grande destaque. Mas o movimento também obteve significantes e orgulhosas conquistas como a aprovação do passe livre (ainda que limitado) nos transportes de regiões metropolitanas de alguns estados (Silva Júnior, 2013).

\section{Discussões e conclusões}

As mobilizações que aconteceram pelo mundo afora nos permitem perceber que, deixando de lado as particularidades dos protestos em cada país, o que chama atenção é o descontentamento dos jovens com a ordem econômica que exalta cada vez mais as desigualdades e, principalmente, com a ordem política que se mostra frágil em reprimir os avanços das misérias sociais e possibilitar a participação dos indivíduos (Silva, 2014).

E quanto ao aspecto desruptivo, assustador, inquietante e não referendado das manifestações, de que ele nos fala? Faz-se importante que os novos e já conhecidos elementos dessas últimas mobilizações sejam problematizados, para nos fazer entender que subjetivação política é possível nos dias atuais e que relação a juventude estabelece com a política. Para Silva Júnior (2013: 105) "as manifestações de junho de 2013 não foram 'gritos no silêncio’ pois desde o ano de 2011 observa-se uma progressão na quantidade de mobilizações no Brasil".

Esses fatos ficarão na história do país, talvez como a maior manifestação social brasileira que incorporou os espaços físicos e virtuais em seu próprio benefício, buscando a efetivação da democracia. Talvez esse ainda seja um tímido começo, que veio com falhas e algumas características a serem aperfeiçoadas, contudo, a sociedade já entendeu que possui, nela mesma, o dis- 
positivo fundamental para emancipação social e desenvolvimento: o poder (Almeida, 2013). Para Žižek (2013), “está claro que não vivemos no melhor mundo possível. Os protestos globais devem servir de lembrança ao fato de que temos a obrigação de pensar em alternativas" (p.108).

Desta forma, neste trabalho foi possível refletirmos sobre as potencialidades da participação juvenil a partir das dinâmicas e movimentos que as Jornadas de Junho produziram no estado de Alagoas. Seguindo os rumos das manifestações em território nacional, em Alagoas a marcha das ruas alcançou resultados semelhantes, como a retenção do aumento da tarifa de transporte público naquele momento.

Através da análise do discurso feito pela mídia local, percebemos que ainda se deve atentar para o fato da juventude ser pouco representada afirmativamente em sua relação com a política, pois em grande parte do tempo que a mídia lançou olhares sobre o tema, os artigos resultantes surgiam com um tom opressor e condenatório.

Devemos, então, compreender o novo cenário político que agora se apresenta para vislumbrar o que poderá acontecer de agora em diante. Que rumos seguiremos para dar continuidade e mantermos viva essa indignação motivadora? Como continuaremos o processo de mobilização da sociedade que deseja interferir efetivamente na construção de uma sociedade democrática? Essas são questões que a juventude das ruas nos ajudaram a pensar e que provavelmente contarão com ela para serem definidas.

\section{Bibliografia}

Abramo, Helena e Venturi, Gustavo (2000). Juventude, política e cultura. Revista Teoria e Debate, 45. Brasil: Editora Perseu Abramo.

Abramovay, Miriam, et al. (2004). Políticas públicas de/para/com juventudes. Brasília: UNESCO.

Almeida, Thiago D’Angelo Ribeiro (2013). Manifestações no Brasil: uma referência de ação política integrada às novas tecnologias da informação. Em: Sousa, Cidoval Morais de; Souza, Arão de Azevedo, Jornadas de junho: repercussões e leituras. Campina Grande: EDUEPB.

Amaral, Roberto (2013). A grande rede e a explosão das ruas. Em: Sousa, Cidoval Morais de; Souza, Arão de Azevedo, Jornadas de junho: repercussões e leituras. Campina Grande: EDUEPB. 
Augusto, Nuno Miguel (2008). A juventude e a(s) política(s): Desinstitucionalização e individualização. Revista Crítica de Ciências Sociais. Coimbra: Universidade de Coimbra.

Brenner, Ana Karina e Carrano, Paulo (2008). Formas e conteúdos da participação de jovens na vida pública. Em: Observatório Jovem do Rio de Janeiro. Rio de Janeiro: Universidade Federal Fluminense.

Castro, Mary Garcia e Abramovay, Miriam (2009). Quebrando mitos: juventude, participação e políticas. Perfil, percepções e recomendações dos participantes da $1^{a}$ Conferência Nacional de Politicas Públicas de Juventude. Brasília: RITLA.

Dayrell, Juarez e Carrano, Paulo (2014). Jovens no Brasil: dificeis travessias de fim de século e promessas de um outro mundo. Rio de Janeiro: Observatório Jovem.

Flick, Uwe (2009). Introdução a Pesquisa Qualitativa. Porto Alegre: Artmed.

Florentino, Renata (2008). Democracia liberal: Uma novidade já desbotada entre jovens. Opinião Pública, 14(1). Campinas.

Harvey, David (2013). “A liberdade da cidade”. Em: Vainer, Carlos et al. Cidades Rebeldes: passe livre e as manifestações que tomaram o Brasil. São Paulo: Boitempo.

Krischke, Paulo (2004). Perfil da juventude brasileira: questões sobre cultura política e participação democrática. Interthesis, 1(2). Florianópolis.

Lima, Venício A. de (2013). Mídia, rebeldia urbana e crise de representação. Em Vainer, Carlos et al., Cidades Rebeldes: passe livre e as manifestações que tomaram o Brasil. São Paulo: Boitempo.

Mayorga, Cláudia (2013). Pesquisar a juventude e sua relação com a política - Notas Metodológicas. Estudos de Psicologia, 18(2). Natal.

Mesquita, Marcos Ribeiro (2009). Identidade, cultura e política: os movimentos estudantis na contemporaneidade. Maceió: Editora da Universidade Federal de Alagoas.

Moreira, Orlandil de Lima e Santiago, Idalina Maria Freitas Lima (2013). Vem pra rua: os protestos de junho. Em: Sousa, Cidoval Morais de; Souza, Arão de Azevedo. Jornadas de junho: repercussões e leituras. Campina Grande: EDUEPB.

Movimento Passe Livre (2013). Não começou em Salvador, não vai terminar em São Paulo. Em: Vainer, Carlos et al., Cidades Rebeldes: passe livre e as manifestações que tomaram o Brasil. São Paulo: Boitempo. 
Nogueira, Silvia Garcia (2013). A Geração 2.0 'faz a hora', vai às ruas e sacode o país. Em: Sousa, Cidoval Morais de; Souza, Arão de Azevedo, Jornadas de junho: repercussões e leituras. Campina Grande: EDUEPB.

Rodrigues, Adriana Alves (2013). Redes sociais e manifestações: mediação e reconfiguração na esfera pública. Em: Sousa, Cidoval Morais de; Souza, Arão de Azevedo. Jornadas de junho: repercussões e leituras. Campina Grande: EDUEPB.

Rolnik, Raquel (2013). As vozes das ruas: as revoltas de junho e suas interpretações. Em: Vainer, Carlos et al., Cidades Rebeldes: passe livre e as manifestações que tomaram o Brasil. São Paulo: Boitempo.

Sakamoto, Leonardo (2013). Em São Paulo, o Facebook e o Twitter foram às ruas. Em: Vainer, Carlos et al., Cidades Rebeldes: passe livre e as manifestações que tomaram o Brasil. São Paulo: Boitempo.

Scherer-Warren, Ilse (2014). Das mobilizações às redes de movimentos sociais. Em: Sociedade e Estado, 21(1). Brasília.

Secco, Lincoln (2013). As Jornadas de Junho. Em: Vainer, Carlos et al., Cidades Rebeldes: passe livre e as manifestações que tomaram o Brasil. São Paulo: Boitempo.

Silva, Conceição Firmina Seixas (2014), A ação coletiva de jovens estudantes universitários e suas formas de organização na universidade e na sociedade contemporânea. Rio de Janeiro: Instituto de Psicologia

Silva Júnior, Nelson Aleixo da (2013). Junho 2013: a juventude nas ruas pra balançar as estruturas. Em: Sousa, Cidoval Morais de; Souza, Arão de Azevedo, Jornadas de junho: repercussões e leituras. Campina Grande: EDUEPB.

Silva Neto, Otacílio Gomes da. Brasil (2013). 2013: reflexões e metáforas. Em: Sousa, Cidoval Morais de; Souza, Arão de Azevedo, Jornadas de junho: repercussões e leituras. Campina Grande: EDUEPB.

Žizek, Slavoj (2013). Problemas no Paraíso. Em: Vainer, Carlos et al., Cidades Rebeldes: passe livre e as manifestações que tomaram o Brasil. São Paulo: Boitempo. 